\title{
UMA REFLEXÃO SOBRE O CONSUMO DE COMUNIDADES VIRTUAIS NO BRASIL
}

\section{A REFLECTION ON CONSUME OF VIRTUAL COMUNITIES IN BRAZIL}

\author{
Roberta Caldas Simões ${ }^{1}$, Sergio Robert de Sant'Anna² e \\ João Gualberto Moreira Vasconcellos ${ }^{3}$
}

\section{RESUMO}

Esse artigo pretende refletir sobre o fenômeno da adesão dos brasileiros às redes sociais, em particular o Orkut, e analisar como as características da sociedade brasileira influenciam nas novas formas de sociabilidade emergentes, como as comunidades virtuais. A discussão teórica parte de um olhar totalizante sobre a sociedade brasileira, entendendo-a como uma sociedade relacional, na qual o fundamental é a relação entre os elementos constituintes do todo, traçando uma analogia entre esta sociedade relacional e a emergência das comunidades virtuais no Brasil. Para isso, foi realizada uma pesquisa bibliográfica, seguida por um olhar sobre a ferramenta do Orkut, tendo como base DaMatta, Lemos, Lévy e Rheingold. Os aspectos levantados neste artigo permitem uma reflexão ainda inicial sobre um dos motivos que podem explicar a rápida adesão dos brasileiros às

\footnotetext{
1 Mestre em Administração pela Universidade Federal do Espírito Santo e Especialista em Administração pela Fundação Getúlio Vargas. Desenvolve pesquisas nas áreas de redes sociais na internet, marketing e consumo.

2 Doutor em Comunicação e Semiótica pela Pontifícia Universidade Católica de São Paulo. Atualmente é Professor Assistente da Universidade Federal do Espírito Santo. Desenvolve pesquisas nas áreas de consumo, relação empresa/consumidor, semiótica das situações, estratégias de manipulação e comércio eletrônico.

3 Doutor em Sociologia - Ecole des Hautes Etudes en Sciences Sociales. Atualmente é professor titular da Universidade Federal do Espírito Santo e Diretor do Grupo Futura. Desenvolve pesquisas nas áreas de cultura organizacional, cultura política brasileira.
} 
comunidades virtuais, além de apresentar algumas características predominantes da sociedade brasileira e sua influência na emergência e fortalecimento das comunidades virtuais no Brasil. Indicamos, por fim, que a intensa presença dos brasileiros nas redes sociais pode ser explicada pelo fato de o Brasil ser constituído por uma sociedade relacional.

Palavras-chave: Comunidades Virtuais. Orkut. Sociedade Relacional.

\section{ABSTRACT}

This paper reflects on the phenomenon of adhesion of the brazilian social networks, in particular, Orkut, and analyze the characteristics of brazilian society influence in the new forms of sociality emerging as virtual communities. The theoretical discussion is part of a totalizing gaze of Brazilian society, understood as a relational society in which the key is the relationship between the elements of the whole, drawing an analogy between this relational society and the emergence of virtual communities in Brazil. For this, we performed a literature search followed by a look on the tool Orkut, based DaMatta, Lemos, Levy and Rheingold. The issues raised in this paper allow further reflection on the initial one of the reasons that may explain the rapid accession of Brazil to virtual communities, and present some predominant features of brazilian society and its influence on the emergence and strengthening of virtual communities in Brazil. Indicated, finally, that the intense presence of brazilians in social networks can be explained by the fact that Brazil is composed of a relational society.

Keywords: Virtual Communities. Orkut. Relational Society.

\section{INTRODUÇÃO}

Qual a melhor forma para entendermos uma sociedade, em especial a brasileira? Para DaMatta (1997), esse entendimento deve ser feito de uma forma totalizante e dinâmica, ou seja, não é possível analisarmos uma sociedade limitando-nos apenas a um ponto de vista e desconsiderando as possíveis relações entre os elementos que a compõem. A sociedade deve ser analisada como um processo complexo e sempre em construção e reconstrução, de maneira que possamos identificar se e como as características desta coletividade influenciam nas práticas sociais dos brasileiros, seja em ambiente virtual ou em ambiente não-virtual.

Atualmente, podemos perceber a forte presença das Novas Tecnologias de Informação e Comunicação (NTICs) e de seus elementos decorrentes - como a cibercultura, as redes sociais virtuais e as comunidades virtuais - no cotidiano das pessoas.

Entretanto, é importante fixarmos nossa atenção ao fato de que o Brasil, hoje em dia, tem uma grande participação em comunidades virtuais, como veremos a seguir. Isso nos leva a algumas questões intrigantes: há alguma ligação entre a forma como se fundamenta a sociedade brasileira e esta significativa participação? O que faz o Brasil ser o que é influencia o consumo das comunidades virtuais pelos brasileiros?

Levantamos, neste artigo, a hipótese de que as principais características da sociedade brasileira influenciam o consumo dos sites de redes sociais, em particular o Orkut. Para tanto, utilizamos analogias entre as categorias sociológicas da casa e da rua, propostas 
por DaMatta (1997), para caracterizar a sociedade brasileira e as práticas sociais dos brasileiros no Orkut.

A fim de embasarmos nossa hipótese, apropriamo-nos de pesquisas realizadas pelo IBOPE, que apresentam dados consistentes sobre os hábitos de consumo dos brasileiros no que se refere às comunidades virtuais. Além disso, foi realizada uma observação não participante na comunidade EU AMO O ORKUT e no perfil de oito membros escolhidos aleatoriamente, com o objetivo de identificar aspectos que remetam ao vínculo relacional, emocional e afetivo do Orkut na vida dos membros desse ambiente. Procuraremos também observar como as categorias sociológicas de DaMatta estão presentes em seus depoimentos e comportamentos.

Para desenvolver essa reflexão, o artigo será organizado em torno de três eixos principais: o primeiro trata de apresentar e discutir alguns aspectos da emergência das NTICs, destacando os conceitos de comunidades, redes sociais e comunidades virtuais; o segundo abordará as principais características da sociedade brasileira e como poderemos analisála; o terceiro abordará a vinculação entre a realidade da sociedade brasileira e sua participação na comunidade virtual Orkut, de forma a delinearmos a similitude entre as práticas sociais dos brasileiros no ambiente "real" e a sua sociabilidade no ambiente virtual.

\section{REDES SOCIAIS E COMUNIDADES VIRTUAIS}

Nesse tópico nos perguntamos: o que são comunidades e quais as suas principais características? Para a grande maioria, a filiação a uma comunidade não é o resultado de uma escolha deliberada, mas uma questão de tradição. Seus membros habitam uma região determinada, têm um mesmo governo e estão irmanados por uma mesma herança cultural e histórica.

A filiação às comunidades sempre ocupou um grande papel na definição de quem uma pessoa é como ser humano, demarcando sua identidade. Neste sentido, a comunidade exercia poder sobre o indivíduo, mais do que o indivíduo sobre a comunidade.

Segundo Recuero (2001), o ser humano sempre foi um animal gregário. Para sobreviver e conseguir reproduzir-se, ele trabalhava em grupos que, mais tarde, evoluíram para as primeiras comunidades. No entanto, podemos encontrar várias definições para o termo comunidade, incluindo no conceito um grupo muito heterogêneo de fenômenos.

No entendimento de Weber (1987), o conceito de comunidade baseia-se em uma orientação de ação social. Para o autor, uma comunidade funda-se em qualquer tipo de ligação emocional, afetiva ou tradicional. Weber $(1987$, p. 77$)$ utiliza como exemplo fundador de uma comunidade a seguinte relação: "chamamos de comunidade a uma relação social na medida em que a orientação da ação social, na média ou no tipo ideal - baseia-se em um sentido de solidariedade: o resultado de ligações emocionais ou tradicionais dos participantes".

Ainda para Weber (1987), a comunidade só existiria propriamente quando sobre uma base de um sentimento de situação comum e de suas consequências está também situada a ação reciprocamente referida e que essa referência traduz o sentimento de formar um todo.

Já para Recuero (2001), o significado de comunidade giraria em torno de dois sentidos. O primeiro refere-se ao lugar físico, geográfico, como uma vizinhança, uma cidade ou 
um bairro. Assim, as pessoas que vivem em um determinado lugar geralmente estabelecem relações entre si, devido à proximidade física e ao fato de viverem sob as mesmas convenções comuns. O segundo significado de comunidade refere-se, segundo a autora, a um grupo social de qualquer tamanho que divide interesses comuns, sejam eles religiosos, sociais, profissionais etc.

Bauman (2003) entende que a palavra comunidade guarda uma sensação de alguma coisa boa, ou seja, comunidade é tudo aquilo que sentimos falta e de que precisamos para vivermos seguros e confiantes. É um lugar "cálido", um lugar confortável e aconchegante que reflete a necessidade de desfrutarmos de um sentido de lugar. Para o autor, portanto, uma comunidade se funda na necessidade de pertencer, não a uma sociedade de forma abstrata, mas a algum lugar particular.

De acordo com Scaraboto (2006), a vizinhança e o parentesco deixaram de ser as únicas possibilidades de formação de laços sociais, principalmente com o advento da rede mundial de computadores que permite que se mantenham relacionamentos sociais ou afetivos a grandes distâncias geográficas. Uma revolução conceitual fez com que a comunidade deixasse de ser definida apenas em termos de espaço, para ser definida em termos de suas características como rede social.

Como já foi observado, o conceito de comunidade evoluiu de um sentido quase ideal de família, de uma comunidade rural, para a um conjunto maior de grupos humanos. Com o advento da modernidade e da urbanização, as comunidades rurais passaram a desaparecer, cedendo espaço para as grandes cidades.

Por essas mudanças, Scaraboto (2006) sugere que é mais proveitoso definir as comunidades não como agregações físicas, mas como redes de laços interpessoais que oferecem sociabilidade, apoio, informação, senso de pertencimento e identidade social.

Características como essas se destacam em um dos mais recentes desdobramentos do conceito de comunidade, originado no próprio elemento transformador em questão: as redes sociais e comunidades virtuais.

De acordo com Ribas e Ziviani (2008) e Recuero (2009), o estudo das redes sociais não é novo. Entre os anos de 1930 e 1970, a Antropologia, a Sociologia e a Psicologia Social já faziam uso do termo redes sociais para designar a intermediação das relações interpessoais e sociais. Com o surgimento das NTICs, houve um redimensionamento do conceito de rede social, o que ampliou seu escopo de aplicação e, consequentemente, seu estudo empírico.

Ainda segundo Ribas e Ziviani (2008), o termo rede além de seu aspecto material ou seja, o seu conjunto de linhas entrelaçadas - é também social e político, devido às pessoas, aos símbolos, às mensagens e aos valores que a compõem. Nesse sentido, ela é considerada pelas autoras como uma abstração e um dado da realidade atual. As redes sociais emergem de processos culturais e políticos, e, por isso, manifestam um desejo coletivo de inovação, como um padrão organizacional capaz de expressar em seu arranjo de relações a vontade de resolver problemas atuais, coletivos e/ou individuais. Cada rede social, por sua vez, possui uma configuração particular que depende do ambiente onde esta se forma e atua; da cultura política de seus membros e dos objetivos compartilhados.

Para Recuero (2009), na Internet, o estudo das redes sociais enfoca o problema de como as estruturas sociais podem surgir, de que tipo são, como são compostas através das NTICs e como essas interações mediadas por computador são capazes de gerar fluxos de 
informações e trocas sociais que podem influenciar suas estruturas. Para estudar estas redes, no entanto, é preciso também estudar seus elementos e seus processos dinâmicos.

Uma rede social, segundo Recuero (2009), consiste em um conjunto de dois elementos, os atores (pessoas, instituições ou grupos) e suas conexões, chamadas de laços sociais. Os atores são o primeiro elemento da rede social. Trata-se de todas as pessoas envolvidas na rede observada. Como partes do sistema, os atores podem modificar estruturas da sociedade através da interação e da constituição de laços sociais.

É importante ressaltar ainda que os atores sociais da Internet são constituídos de uma forma distinta da comunicação não-virtual. Por causa do distanciamento existente entre os envolvidos na interação social virtual, que é considerada a principal característica da comunicação mediada por computador, os atores não são imediatamente discerníveis. Assim, neste caso, trabalha-se com representações dos atores sociais ou com construções identitárias do ciberespaço. ${ }^{4}$ No ciberespaço, considera-se, inicialmente, que não são os atores sociais que atuam, mas sim suas representações. Assim, as redes sociais são espaços de interação - lugares de fala - constituídos por atores sociais virtuais que podem expressar elementos de sua personalidade ou individualidade. Assim, segundo Recuero (2009, p. 27), um primeiro aspecto relevante para o estudo do ciberespaço é a característica da expressão pessoal ou personalizada na Internet :

[...] entender como os atores constroem esses espaços de expressão é também essencial para compreender como as conexões são estabelecidas. É através dessas percepções que são construídas pelos atores que padrões de conexões são gerados.

Em relação aos laços sociais, segundo elemento de composição de uma rede social, indica-se que estes são compostos por relações sociais, que, por sua vez, são compostas por interações sociais ${ }^{5}$ (RECUERO, 2009).

Percebemos que o grande potencial existente no contexto das redes sociais se refere ao fato de que a informação não se encontra mais centralizada em um único local ou indivíduo. O detentor dessas informações, portanto, não é mais uma única pessoa, pois se ampliaram as fontes de informação e a intensidade de trocas informativas entre os participantes de determinada rede. As conexões existentes através das interações estabelecidas nas redes sociais virtuais criam possibilidades para que as pessoas atuem como multiplicadoras e organizadoras de uma comunidade qualquer. Esses atores específicos, então, compartilham informações, pesquisas e dados relevantes para sua comunidade.

\footnotetext{
4 Segundo Lemos (1996), ciberespaço pode ser entendido sob duas perspectivas: como um lugar onde estamos quando entramos em um ambiente virtual (ou realidade virtual); ou como um conjunto de redes de computadores, interligadas ou não, em todo o planeta. Ampliando a compreensão sobre o ciberespaço, Lévy (1999) define-o como sendo: um espaço de comunicação virtual que não se opõe ao real, mas que o complexifica; um espaço público, imaterial; e que é constituído através da circulação de informações.

${ }^{5}$ Recuero (2009) ainda esclarece que uma interação social é uma ação que tem um reflexo comunicativo entre o indivíduo e seus pares. Sendo assim, uma interação social pode ser considerada como uma manifestação comunicacional com reflexos sociais, que, se repetida, pode gerar relações sociais. 0 conteúdo de uma relação social é definido por Recuero (2009) como um capital social que é entendido como tudo o que é trocado entre os pares através de interações sociais como as informações, sentimentos, suportes, conhecimentos, dentre outros.
} 
Podemos perceber que as NTICs, ao permitirem a criação de redes sociais virtuais tais como blogs, chats, comunidades virtuais, dentre outros -, estimulam e, de certa forma, favorecem a reinvenção de algumas práticas sociais já institucionalizadas em nossa sociedade.

No entanto, em relação à criação de redes sociais virtuais, Recuero (2009, p. 102) defende que a expressão das redes sociais na Internet pode ser resultado de um tipo de uso que os atores sociais fazem dos sites de redes sociais, visto que há uma diferença entre redes sociais na Internet e sites de redes sociais, como Orkut, Twitter, Blogs etc. Ou seja, sites de redes sociais são espaços utilizados para a expressão das redes sociais na Internet

Ainda segundo Recuero (2009) os sites de redes sociais podem ser definidos como sistemas que permitem: i) a construção de uma persona através de um perfil ou página pessoal; ii) a interação através de comentários; e iii) a exposição pública da rede social de cada ator. Os sites de redes sociais são uma categoria de softwares sociais com aplicação direta na comunicação mediada por computador.

Um aspecto que merece atenção é o fato desses sites - tais como o Orkut, entre outros - permitirem a visibilidade e a articulação de redes sociais, além da manutenção dos laços sociais estabelecidos no espaço não virtual.

Segundo Recuero (2009, p. 104), embora os sites de redes sociais atuem como suportes para as interações que constituirão as redes sociais, eles não são por si só, redes sociais.

\footnotetext{
Sites de redes sociais propriamente ditos são aqueles que compreendem categorias dos sistemas focados em expor e publicar as redes sociais dos atores. São sites cujo foco principal está na exposição pública das redes conectadas aos atores, ou seja, cuja finalidade está relacionada à publicização dessas redes.
}

A utilização de softwares que oferecem suporte às redes sociais já existentes no ambiente não virtual leva-nos à discussão do conceito de comunidade virtual.

Este conceito se desenvolveu principalmente com a influência da Comunicação Mediada por Computador (CMC). No entanto, não há um consenso sobre sua terminologia já que é possível encontrar expressões como comunidades on-line, comunidades virtuais ou comunidades mediadas por computador. Para fins deste trabalho, optamos pelos termos comunidade on-line e comunidades virtuais como sinônimos.

Apesar de diferentes terminologias, pesquisadores de várias áreas (como CASTELLS, 1999; RECUERO, 2009, dentre outros) apontam como sendo a mais abrangente, a definição de Rheingold (1996), que foi um dos primeiros autores a efetivamente utilizar o termo comunidade virtual para os grupos humanos que estabeleciam e mantinham relações sociais no ciberespaço. Para Rheingold (1996, p. 18), "As comunidades virtuais são os agregados sociais surgidos na rede, quando os intervenientes de um debate o levam por diante em número e sentimento suficientes para formarem teias de relações pessoais no ciberespaço".

Segundo Rheingold (1996), a origem das comunidades virtuais remonta o fim da década de 1970, quando uma rede de computadores pessoais ampliou a participação dos 
indivíduos em discussões virtuais, que até então possuíam apenas finalidades militares e de pesquisa.

Sobre a origem das comunidades on-line, Scaraboto (2006) afirma que estas se iniciaram como eventos sociais espontâneos em redes eletrônicas e que quanto mais indivíduos aderiam a estas redes mais agrupamentos sociais se formavam. Esses agrupamentos foram, com o tempo, segmentados por interesses comuns, o que solidificou os laços entre os indivíduos e os conduziu a uma caracterização de comunidades.

Em seu estudo, Scaraboto (2006) levanta alguns critérios que podem definir se um agrupamento na Internet é ou não é uma comunidade on-line, são eles: a) os membros desse agrupamento devem ter uma participação ativa e autossustentável no conjunto, ou seja, devem ser um grupo de participantes regulares; b) o agrupamento deve compartilhar histórias, propósitos, cultura, normas e valores; c) os membros desse agrupamento devem apresentar solidariedade, apoio e reciprocidade entre si; d) nesse agrupamento devem existir críticas, censuras, conflitos e formas de resolução desses conflitos; e) deve existir também uma autoconsciência do grupo como entidade distinta de outros grupos; e f) no grupo devem surgir papéis, controle e rituais.

Para Rheingold (1996), a comunicação mediada por computador veicula e reflete os nossos códigos culturais, o nosso subconsciente social e o nosso autoconceito. Dessa forma, faz-se interessante refletirmos sobre a realidade das comunidades virtuais na sociedade brasileira. Tal assunto, portanto, será tema de nossa próxima seção.

\section{O CONSUMO DE COMUNIDADES VIRTUAIS NO BRASIL: O ORKUT}

O Orkut é um site de rede social filiada à empresa Google, criado em 24 de janeiro de 2004 , com o objetivo de ajudar seus membros a conhecer pessoas e manter relacionamentos. Neste site, o participante pode escolher que comunidade quer participar e ainda disponibilizar suas informações espontaneamente a outros usuários da rede ao descrever seu perfil e ao compartilhar com os outros suas comunidades de preferência, fotos e vídeos. Enfim, o usuário pode compartilhar com os demais usuários da rede a sua própria identidade ao mesmo tempo em que também pode observar as experiências, gostos e preferências de outros usuários.

Segundo dados do IBOPE/NetRatings ${ }^{6}$ (2008), em maio de 2008, 20,6 milhões de pessoas, considerando a Internet residencial brasileira, navegaram em sites das subcategorias Comunidades. ${ }^{7}$ Isso, portanto, equivalente a $88,6 \%$ do total dos internautas ativos.

\footnotetext{
O IBOPE/NetRatings realizou uma pesquisa quantitativa no primeiro semestre de 2008 com o objetivo de demonstrar o uso de redes sociais pelos brasileiros, em especial, o uso das comunidades virtuais, comparativamente a outros países. Esta pesquisa ressaltou aspectos como: quantidade de usuários domiciliares que navegam em comunidades on-line; principais comunidades utilizadas; e tempo gasto em cada comunidade. A fim de favorecer a comparação, foi utilizada a mesma metodologia, baseada na audiência domiciliar, em dez países: Alemanha, Suiça, Austrália, Estados Unidos, Reino Unido, Itália, Espanha, França, Japão e Brasil.

7 Comunidades incluem sites como as redes sociais Orkut e MySpace, os blogs, os microblogs, os bate-papos, os fóruns, os grupos de discussão, os mundos virtuais e outros sites assemelhados que reúnem grupos de interesse e de relacionamento.
} 
Enquanto no Brasil cada usuário da subcategoria Comunidades as utiliza em média por quase cinco horas, em outros países o consumo é muito menor. Com exceção do Reino Unido, onde o consumo é de cerca de 2 horas e meia por mês, nos outros países o consumo de comunidades, blogs e grupos não passa de 2 horas (Tabela 1).

Ainda conforme pesquisa do IBOPE/NetRatings (2008), o Brasil tem a maior concentração de usuários na subcategoria Comunidades, entre os dez países medidos com a mesma metodologia. Depois do Brasil (78,2\%) vem o Japão, com $67,1 \%$ de seus internautas navegando mensalmente em comunidades; a França, com 60,9\%; a Espanha, com 59,6\%; a Itália, com 59,0\%; o Reino Unido, com 56,6\%; e os Estados Unidos, com 56,3\%.

TABELA 1 - Subcategorias comunidades - audiência domiciliar em dez paises

\begin{tabular}{l|c|c|c|c|l}
\hline \multicolumn{1}{c|}{ Países } & $\begin{array}{c}\text { Usuários } \\
\text { únicos (em } \\
\text { milhões) }\end{array}$ & $\begin{array}{c}\text { Alcance } \\
(\%)\end{array}$ & $\begin{array}{c}\text { Visitas por } \\
\text { pessoa }\end{array}$ & $\begin{array}{c}\text { Tempo por } \\
\text { pessoa }\end{array}$ & \multicolumn{1}{|c}{$\begin{array}{c}\text { Maior audiência dentro da } \\
\text { categoria }\end{array}$} \\
\hline Brasil & 17,541 & 78.2 & $\mathbf{1 5 . 2}$ & $\mathbf{0 4 : 3 1 : 1 8}$ & Blogs e comunidades \\
\hline Japão & 32,401 & 67.1 & $\mathbf{1 1 . 7}$ & $\mathbf{0 1 : 4 3 : 4 4}$ & Blogs \\
\hline França & 14,947 & 60.9 & $\mathbf{8 . 2}$ & $\mathbf{0 1 : 0 8 : 4 5}$ & Blogs \\
\hline Itália & 10,744 & 59 & $\mathbf{8 . 7}$ & $\mathbf{0 1 : 2 4 : 0 6}$ & Blogs e comunidades \\
\hline Espanha & 8,788 & 59.6 & $\mathbf{9}$ & $\mathbf{0 1 : 2 7 : 3 2}$ & Blogs \\
\hline Reino Unido & 15,490 & 56.6 & $\mathbf{9 . 5}$ & $\mathbf{0 2 : 3 8 : 1 6}$ & Comunidades \\
\hline EUA & 85,199 & 56.3 & $\mathbf{9 . 5}$ & $\mathbf{0 1 : 5 0 : 0 0}$ & Comunidades \\
\hline Austrália & 5,789 & 52.2 & $\mathbf{9 . 7}$ & $\mathbf{0 1 : 4 4 : 1 3}$ & Comunidades \\
\hline Suíça & 1,641 & 42.7 & $\mathbf{5 . 8}$ & $\mathbf{0 1 : 0 1 : 4 6}$ & Blogs \\
\hline Alemanha & 13,524 & 37.7 & $\mathbf{8 . 4}$ & $\mathbf{0 1 : 3 6 : 3 1}$ & Blogs e comunidades \\
\hline
\end{tabular}

Fonte: NetView - IBOPE/NetRatings (2008)

Podemos dizer que as comunidades virtuais, de uma maneira geral, possuem uma participação expressiva entre os brasileiros, visto que, entre os países comparados, somente o Brasil chegou a um tempo mensal por pessoa tão alto, ficando, em abril, com 4 horas e 31 minutos.

Dentre as comunidades on-line mais consumidas pelos brasileiros, conforme o IBOPE/ NetRatings (2008), destaca-se o Orkut, com cerca de 70\% da audiência, o que o torna o site de rede social mais utilizado no Brasil.

Diante dos dados mencionados, podemos inferir que o Brasil, diferente de outros países, assimilou de forma rápida a lógica das redes sociais e das comunidades virtuais. Desse forma nos cabe indagar: a que podemos atribuir esse fato?

A fim de tentar explicar essa questão, utilizaremos as proposições de DaMatta (1986; 1997) acerca das principais características da sociedade brasileira e como ela pode ser entendida, para construirmos uma analogia capaz de explicar o fenômeno da assimilação das comunidades on-line pelos brasileiros. 
Para DaMatta (1986), definimos nossa sociedade por meio de suas manifestações mais oficiais e mais nobres, isto é, a partir das vozes "cultas" desta coletividade. No entanto, para entendimento do Brasil, segundo o autor, não devemos nos restringir a essa visão exclusivamente oficial e bem-comportada dos manuais de história. O Brasil pode ser encontrado em toda parte, seja no tipo de comida a ingerir, na forma de produzir, na forma de consumir, na forma de se relacionar com as pessoas etc. A diferença nesses aspectos é como os homens e as sociedades se definem por seus estilos, seus modos de fazer as coisas.

Devido à existência deste lado "não oficializado", mas nem por isso desinstitucionalizado em nossa sociedade, somos levados a descobrir, segundo DaMatta (1986), que existem dois modos básicos de construir a identidade brasileira. Em um deles, utilizamos dados precisos e objetivos, como as estatísticas demográficas e econômicas os dados do PIB, PNB e os números da renda per capita e da inflação, bem como os dados relativos ao sistema político e educacional do país. No outro modo de classificação, a identidade da sociedade brasileira se constrói por meio de dados qualitativos, como o tipo de música e comida, as relações que estabelecemos no decorrer da nossa vida, a forma como misturamos vários aspectos para resolvermos questões do cotidiano etc. (DAMATTA, 1986).

Dessa forma, para objetivos deste artigo, adotaremos o conceito de sociedade proposto por DaMatta (1997, p. 13), na qual a sociedade é uma entidade percebida de modo globalizado, como um sistema:

[...] um sistema que tem suas próprias leis e normas. Normas que, se obviamente precisam dos indivíduos para poder se concretizar, ditam a esses indivíduos como é que devem ser atualizadas e materializadas. Aqui a sociedade é uma entidade que se faz e refaz por meio de um sistema complexo de relações sociais, elos que se impõem aos seus membros, indicando - tal como acontece numa peça de teatro ou num cerimonial - tudo aquilo que é estritamente necessário tudo o que é dispensável ou superficial para que se possa criar e sustentar o evento que se deseja construir.

Dessa forma, o autor defende que sem entender a sociedade em suas redes de relações sociais e valores não podemos interpretar como o espaço é concebido. É necessário, então, estudar o peso e o valor das relações e das teias de relações que ligam os indivíduos entre si, fazendo com que vivam num mundo pleno de lógicas. Há a lógica individual de cada um; há a lógica da moralidade social que orienta a ação de todos; e há a lógica das relações que todos estabelecem entre si e com a ideologia como um todo. É a partir deste quadro complexo que as sociedades dão ênfase às relações ou aos indivíduos (DAMATTA, 1997).

O segredo para entender o Brasil é considerá-lo como uma sociedade relacional, onde reside a possibilidade de estudar aquilo que está "entre" as coisas. Diante disso, "[...] o estilo brasileiro se define a partir de um ' $\&$ ', um elo que permite batizar duas entidades e que, simultaneamente, inventa seu próprio espaço" (DAMATTA, 1997, p. 103).

No Brasil essa relação pode ser considerada um dado básico para qualquer situação. "Nesse sentido, o que tipifica o caso brasileiro seria essa institucionalização ou 
autonomização do relacionamento, e do elemento relacional" (DAMATTA, 1997, p. 104). O fundamental para o brasileiro seria, segundo o autor, o juntar, confundir, conciliar, incluir, mas jamais excluir.

Nas propostas de DaMatta as "categorias sociológicas" ${ }^{8}$ da casa e da rua são colocadas como sendo importantes para a compreensão da sociedade brasileira. A gramática ideológica brasileira da casa e da rua não se refere somente a uma divisão geográfica ou a apenas uma divisão física da sociedade, mas às esferas de ação e significado social de onde se constroem e se vislumbram toda a estrutura e desenvolvimento dessa sociedade.

Esses espaços demarcam áreas de significação social, na medida em que eles operam como focos de muitas coisas. Apoiados em DaMatta (1997, p. 19), podemos ler o Brasil do ponto de vista da casa e da rua, já que essas possibilidades estão institucionalizadas entre nós.

[...] Leituras pelo ângulo da casa ressaltam a pessoa. São discursos arrematadores de processos e situações. Sua intensidade emocional é alta. Aqui a emoção é englobadora, confundindo-se com o espaço social que está de acordo com ela. Nesses contextos, todos podem ter sido adversários ou até mesmo inimigos, mas o discurso indica que também são "irmãos" porque pertencem a uma mesma pátria ou instituição social. Leituras pelo ângulo da rua são discursos muito mais rígidos e instauradores de novos processos sociais. É o idioma do decreto, da letra dura da lei, da emoção disciplinada que, por isso mesmo, permite a exclusão, a cassação, o banimento, a condenação.

É importante destacar que a gramática da casa não é somente o equivalente ao espaço público em oposição ao espaço privado, mas é uma dimensão social de onde todo universo social é ordenado sob uma determinada perspectiva. Não se trata de um espaço complementar ao mundo público - como o interno se opõe ao externo e o complementa mas também de uma dimensão que, muitas vezes, abarca todo o universo social fazendo desaparecer as outras dimensões. Normalmente, casa e rua se complementam e se firmam em um dinamismo de segmentações e exclusões, mas há ocasiões em que cada uma delas pode englobar todas as outras, fazendo com que o sistema fique submetido à sua ética ou lógica social. (DAMATTA, 1997).

Portanto, ao considerarmos que a casa e a rua são sistemas simbólicos que estão presentes e que regem a sociedade brasileira, torna-se interessante pensar em como esta mesma lógica se apresenta diante da emergência das Novas Tecnologias de Informação e Comunicação (NTICs) e das formas de socialização no ambiente virtual. Afinal, como podemos exercitar o entendimento da articulação da lógica relacional da sociedade brasileira com a lógica que rege as comunidades virtuais, em especial o Orkut?

\footnotetext{
- O autor utiliza "categoria sociológica" como um conceito que pretende dar conta daquilo que uma sociedade pensa e assim institui como seu código de valores e ideias: sua cosmologia - estrutura e progresso - e seu sistema classificatório; e também para traduzir aquilo que a sociedade vive e faz concretamente - o seu sistema de ação que é referido e embebido nos seus valores.

9 Disponível em: < http://www.orkut.com.br/Main\#Community.aspx?cmm=2460091>. Acesso em: 27 jul. 2009. Esta comunidade foi criada em 10 de junho de 2005 e possui 60.624 membros. A comunidade EU AMO O ORKUT foi escolhida para ser motivo de análise por reunir elementos representativos para os objetivos deste artigo.
} 
Se observarmos, por exemplo, uma comunidade presente no Orkut, denominada: EU AMO O ORKUT ${ }^{9}$ como um agrupamento virtual de pessoas que, declarada e espontaneamente, manifestam seu vínculo com a ferramenta do Orkut, podemos identificar vários aspectos que remetem ao vínculo relacional, emocional e afetivo do Orkut na vida dos membros deste "mundo virtual", em especial a partir das respostas ${ }^{10}$ a um dos fóruns disponíveis que traz a pergunta: Qual a importância do Orkut na sua vida?

o orkut na minha vida nossa o orkut pra mim é tudo, todos os dias antes de qualquer coisa abro meu orkut, ñ consigo ficar um dia se quer sem ver meus recadinhos. so apaixonada mesmo! eu e o orkut= amor eterno. bjux*" (Membro1)

"naum consigo fica sem o orkut. i love you orkut. tds os dias abro o orkut qse td hr to on" (Membro 2)

"Entrei nessa d orkut meio tarde em relação as outras pessoas e adoro esse mundo.

Ñ soh o lance $d$ amizades mas tbm as comus são muito legais pq consigo muitasdicas sobre o q estudo como webdesing, a lingua italiana e outras coisas $d$ interesse em geral... Além da diversão eh claro, eu aprendo muito no orkut. ;-)" (Membro 3)

O vínculo relacional, emocional e afetivo fica explícito quando os membros manifestam que o Orkut é tudo para sua vida e que não conseguem ficar sem ele.

Podemos perceber que do conjunto mesclado de relações sociais que se instaura nas comunidades virtuais, uma parte delas vem de práticas sociais herdadas e institucionalizadas na sociedade brasileira, como a forte presença das relações; outras são proporcionadas pela própria emergência das NTICs, como a superação das fronteiras físicas, a aproximação instantânea das pessoas e a planificação dos contatos; e, por último, as novas relações virtuais, que resultam no sistema de produção colaborativa, em novas formas de empoderamento e na propagação da liberdade do conhecimento como princípio.

Esse novo quadro exige redirecionar o olhar analítico sobre as formas de sociabilidade engendradas pelas NTICs, e, para isso, realizaremos algumas analogias entre as características predominantes da sociedade brasileira e as comunidades virtuais, a fim de tentarmos explicar o motivo da rápida assimilação de ferramentas como o Orkut entre os brasileiros.

Uma das características da sociedade brasileira que se destaca, é justamente a força das relações, e, ao que parece, a lógica que predomina no Orkut é similar ao fato da sociedade brasileira ser, aos moldes de DaMatta, relacional. Isso quer dizer que em uma sociedade, na qual as relações estão em primeiro lugar, encontrar um espaço, mesmo que virtual, para fortalecer relações sociais, é um estímulo para que haja uma compatibilidade e assimilação imediata.

Para exemplificar nossa afirmação, acessamos a página inicial do Orkut (Figura 1), na qual podemos encontrar três frases curtas que se constroem de forma imperativa, dando destaque às palavras: Conecte-se; Conheça; e Compartilhe.

\footnotetext{
${ }^{10}$ As respostas foram apresentadas exatamente como estavam na respectiva comunidade, inclusive com os erros de português e grafia.
} 


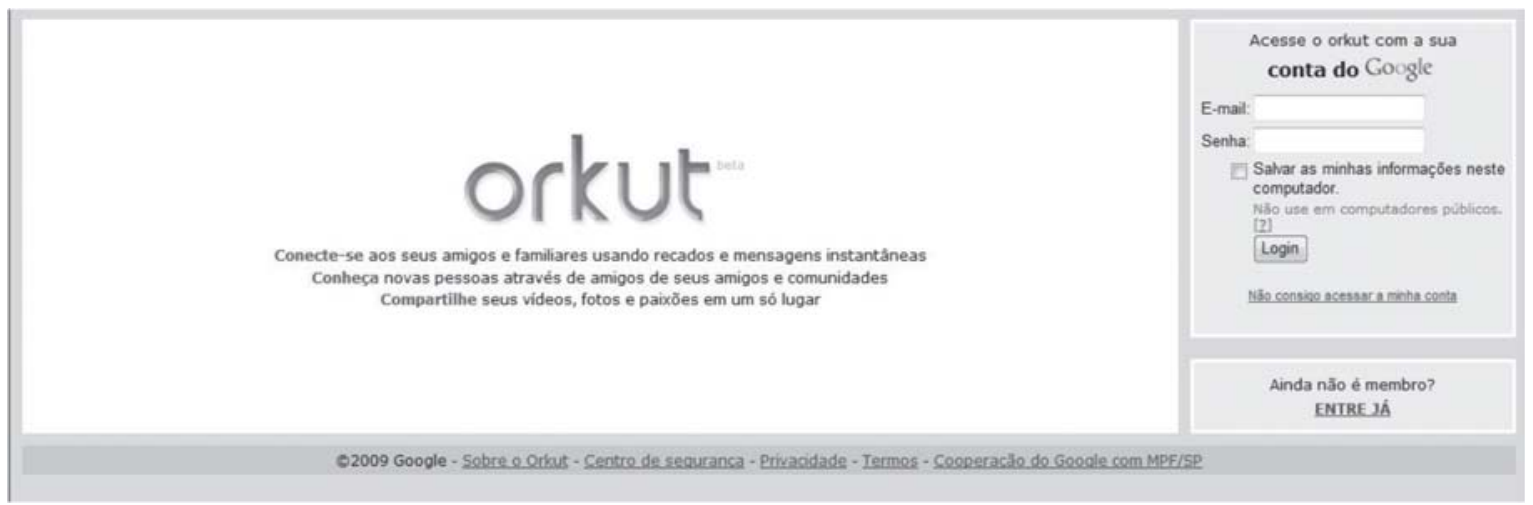

FIGURA 1 - Página Inicial Do Orkut

FONTE: www.orkut.com (acesso em: 16 jan. 2009)

Outro aspecto que reforça nossas ideias quanto ao aspecto relacional do Orkut é a própria descrição da ferramenta, no link: "Sobre o Orkut":

O orkut é uma comunidade on-line criada para tornar a sua vida social e a de seus amigos mais ativa e estimulante. A rede social do orkut pode ajudá-lo a manter contato com seus amigos atuais por meio de fotos e mensagens, e a conhecer mais pessoas.

Com o orkut é fácil conhecer pessoas que tenham os mesmos hobbies e interesses que você, que estejam procurando um relacionamento afetivo ou contatos profissionais. Você também pode criar comunidades on-line ou participar de várias delas para discutir eventos atuais, reencontrar antigos amigos da escola ou até mesmo trocar receitas favoritas.

Você decide com quem quer interagir. Antes de conhecer uma pessoa no orkut, você pode ler seu perfil e ver como ela está conectada a você através da rede de amigos.

Para ingressar no orkut, acesse a sua Conta do Google e comece a criar seu perfil imediatamente. Se você ainda não tiver uma Conta do Google, nós o ajudaremos a criá-la em alguns minutos.

Nossa missão é ajudá-lo a criar uma rede de amigos mais íntimos e chegados. Esperamos que em breve você esteja curtindo mais a sua vida social. Divirta-se (= " (ORKUT, acesso em 16 de janeiro de 2009)

Podemos perceber que, a todo o momento, o apelo é para o relacionamento, para a intensificação das relações sociais dos sujeitos. É como se, ao entrar neste ambiente, o indivíduo tivesse magicamente suas relações sociais fortalecidas, estreitadas, e, para os que têm pouca vida social no mundo real, o Orkut aparece como uma solução para o isolamento, a solidão e a infelicidade.

Para Oldenburg (1991), existem três lugares essenciais na vida: onde vivemos, onde trabalhamos e onde nos reunimos para conviver. No mesmo raciocínio, o autor continua 
defendendo que esses espaços públicos de convívio, regados a conversas informais, são onde as comunidades se consumam e se mantém. No entanto, estes "terceiros lugares" estão aos poucos sendo eliminados devido às transformações pelas quais passa a sociedade contemporânea.

Segundo Rheingold (1996), o ciberespaço pode ser um desses lugares públicos informais - "terceiros lugares" - onde podemos reconstruir os aspectos comunitários perdidos. Dessa maneira, o Orkut é uma comunidade que emerge no ciberespaço, situando-se em um terreno neutro e serve para reduzir os participantes à mesma condição social. $A$ atividade primária característica desses "terceiros lugares", tal como no ciberespaço, é a conversação, que desempenha o papel de principal veículo de exposição e apreciação da personalidade e individualidade humana. O caráter dos "terceiros lugares" é majoritariamente determinado pela clientela habitual e caracteriza-se por um ambiente divertido, em contraste com o ar mais sério de outras esferas sociais. "Embora constituam um cenário radicalmente diferente do lar, os terceiros lugares assemelham-se notavelmente a um 'doce lar' pelo conforto e apoio psicológico que proporcionam" (RHEINGOLD, 1996, p. 42).

Tal como para o entendimento de uma sociedade, para o entendimento do ciberespaço é importante compreendermos suas redes de relações e valores.

Dessa forma, diante da identificação das similitudes entre a lógica relacional que rege a sociedade brasileira e o Orkut, acreditamos que a adoção das mesmas categorias sociológicas da casa e da rua propostas por DaMatta, também podem ser utilizadas para analisarmos a dinâmica presente nas comunidades virtuais. Sobre estas categorias este autor esclarece que:

Quando digo então que 'casa' e 'rua' são categorias sociológicas para os brasileiros, estou afirmando que, entre nós, estas palavras não designam simplesmente espaços geográficos ou coisas físicas comensuráveis, mas acima de tudo entidades morais, esferas de ação social, províncias éticas, dotadas de positividade, domínios culturais institucionalizados e, por causa disso, capazes de despertar emoções, reações, leis, orações, músicas e imagens esteticamente emolduradas e inspiradas. (DAMATTA, 1997, p. 15).

Aplicando estas categorias sociológicas como áreas de significação social, podemos ler o espaço da casa como a individualidade e identidade do usuário nas comunidades; e o espaço da rua como o ciberespaço.

Segundo DaMatta (1997), mais importante do que estudar as partes - casa e rua individualmente ou em contraposição é entender a relação entre os elementos, a conexão entre eles existente a fim de compreendermos o fato em sua totalidade.

Dessa forma, ao analisarmos o significado das comunidades on-line, em particular o Orkut, podemos inferir que os brasileiros encontram neste espaço o ambiente ideal para realizar a conexão entre o espaço da casa e da rua. Isso porque o Orkut dá aos seus usuários a possibilidade de manifestar o universo da rua e o universo da casa ao mesmo tempo, sem que ocorra qualquer "choque" entre essas manifestações.

Conforme DaMatta (1997), o espaço da rua é caracterizado pela emoção disciplinada - espaço regido pelas normalizações da "letra dura da lei" no qual é permitido a exclusão, 
o banimento e a condenação. Dessa maneira, o discurso que rege o espaço da rua instaura novos processos sociais.

Quando realizamos uma imersão no Orkut para averiguar nossas hipóteses, percebemos que, como qualquer comunidade, esta também é regida por algumas normas que regulam os comportamentos individuais e coletivos, o que poderíamos chamar de Estatuto da Comunidade. Neste estatuto, a comunidade Orkut.com ressalta a responsabilidade que cada um tem consigo mesmo e com os outros. Em cada página há um link chamado "Denunciar abuso" que poderá ser acionado por qualquer usuário. Em seguida, a denúncia será averiguada pela equipe do Orkut.

Neste estatuto constam normas e regulamentos sobre as restrições nos perfis ${ }^{11} \mathrm{e}$ nas comunidades. É interessante notar que as restrições têm como base as leis válidas no "mundo real" (expressão usada no site do Orkut), além de não permitir utilização comercial do Orkut, somente pessoal, salvo casos acordados com o Google, antecipadamente.

Existem também outras políticas do Orkut.com, tais como Termo de serviço, Política sobre material protegido por direitos autorais e Política de privacidade.

Pelo exposto, podemos perceber que o Orkut é um espaço virtual que permite que os cidadãos/usuários se encontrem para conversar, contar mexericos, discutir, avaliar-se e encontrar os pontos fracos das ideias que estão postadas na comunidade. No entanto quem não tiver práticas sociais compatíveis com as estabelecidas pela comunidade poderá ser banido do convívio deste espaço, podendo ser denunciado pelos próprios participantes da mesma.

A leitura pela ótica da casa, conforme aponta DaMatta (1997), ressalta que a pessoa pode possuir discursos com alta intensidade emocional, na qual a emoção é englobadora e pode confundir-se com o espaço social que está de acordo com ela. O discurso, então, indica que todos neste espaço são "irmãos" justamente por compartilharem o mesmo ambiente.

Podemos perceber essa carga emocional presente no Orkut quando os usuários descrevem o seu perfil (Figura 2) e inserem fotos com seus amigos, parentes e dos lugares por onde já passou. A mesma relação também se apresenta quando o usuário disponibiliza vídeos e músicas preferidas e escolhe que pessoas podem participam do seu grupo de relacionamento. Quanto a este último aspecto, podemos dizer que ele se estabelece por gradações de vínculo emocional, com a utilização de palavras como conhecido, amigo, bom amigo, não conhece, é do trabalho, dentre outras categorias.

O que torna a análise interessante é justamente o englobamento de um espaço pelo outro de forma que a própria rua pode ser vista e manipulada como se fosse um prolongamento ou parte da casa, ao passo em que zonas da casa podem ser percebidas em certas situações como parte da rua (DAMATTA, 1997).

Um exemplo significativo do primeiro caso é a dificuldade em demarcar com nitidez os limites da individualidade e o espaço público do Orkut, pois há uma confusão entre o que é público e o que é de foro íntimo. Para o segundo caso, podemos ilustrar com o fato de

\footnotetext{
${ }^{11}$ Podemos entender Perfil como um sumário ou conjunto de informações sobre uma pessoa em uma rede social virtual.
} 
FIGURA 2 - descrição do perfil de usuário

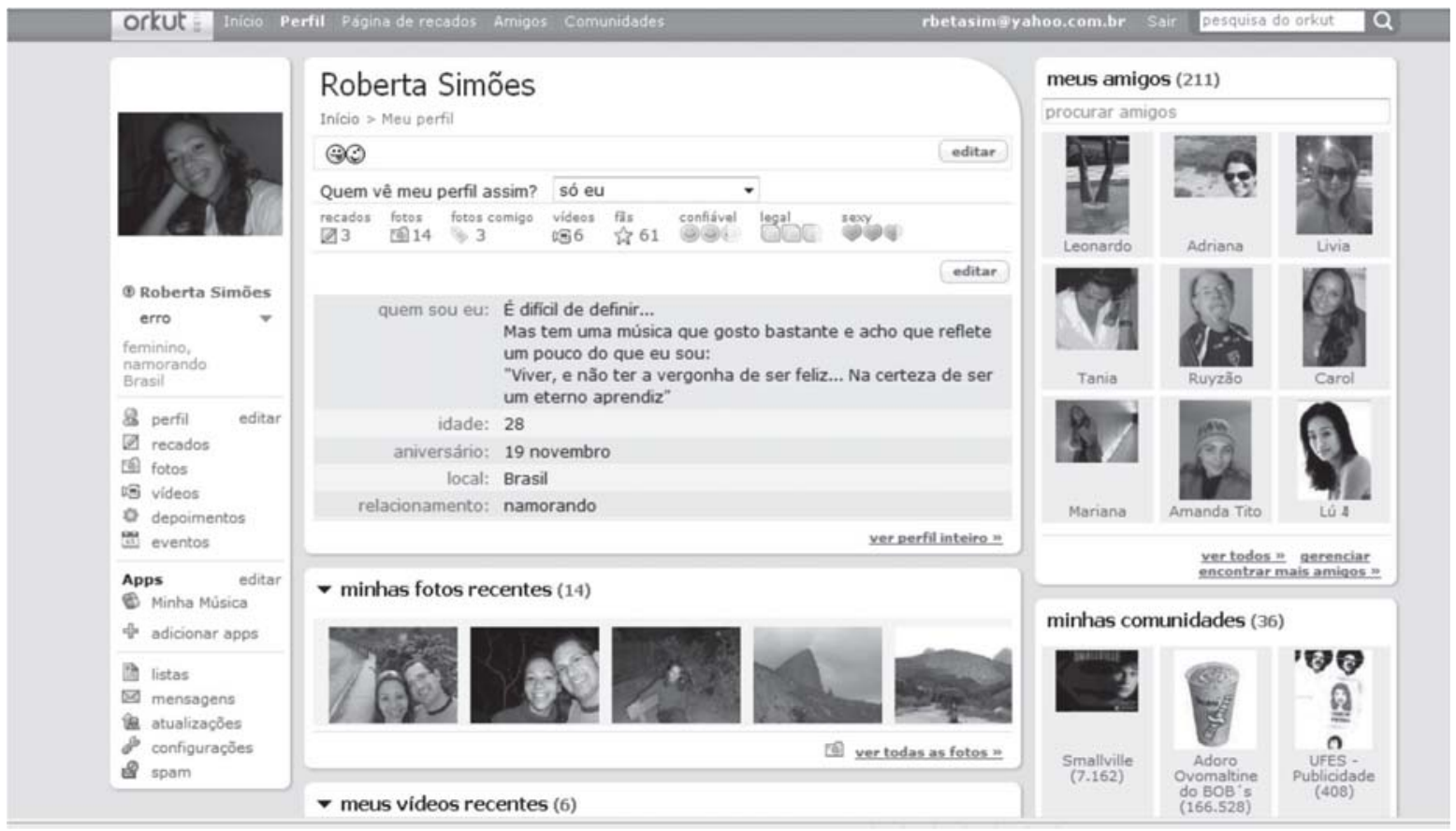

FONTE:http://www.orkut.com.br/Main\#Profile.aspx?rl=ls\&uid=16771773526034046856 (Acesso em: 16 jan. 2009).

que cada usuário pode exibir em seu perfil suas fotos pessoais, seus recados e os depoimentos feitos para ele, numa espécie de exposição permanente - como podemos observar a seguir nos recados exibidos nos perfis de alguns membros da comunidade EU AMO $O$ ORKUT que foram selecionados aleatoriamente:

AI BELA..

TERMINEEII MEISMOO..

MAS TEM HORA Q FICO TRISTE MAS DEPOIS PASSA..

SEI LA AHCO Q TERMINEI POR DOIDEIRA MINHA..

FODA..

SE ARREPENDIMENTENTO MATASSE NE BJUUU=D" (Membro 7)

bomdia!!!!

e ai como vc tá????

ontem esqueci de te dizer do sonho mórbido que tive com minha mãe,acho que esses sonhos querem me dizer alguma coisa, mas não consigo decifrá-lo....

mas não gostei nada, depois te conto, pede pra rezar uma missa pra ela por favor....

muito obrigada amiga....

vc eu sei que gosta de mim de verdade,sem mentiras ou falsidades.... bjussssssssss

depois agente se fala (Membro 8) 
A partir desses fragmentos, podemos notar que os usuários expõem publicamente suas ações e sentimentos no Orkut ao estabelecerem uma conversação com outro membro desconsiderando o fato de sua conversa estar visível para todos os membros daquela rede. Dessa forma, o que deveria referir-se apenas àqueles dois membros passa a fazer parte de uma esfera pública.

Esta dificuldade em demarcar os limites do individual e do social remete à concepção de Dumont (1985), na qual ao lado do conceito de um indivíduo que constitui o valor supremo - caracterizando o individualismo - teremos o indivíduo que se encontra na sociedade como um todo, caracterizando o holismo.

Segundo Dumont (1985), o termo indivíduo designa duas coisas ao mesmo tempo: um objeto fora de nós e um valor. O primeiro é um sujeito empírico que fala, pensa e quer, é o modelo individual da espécie humana que se encontra em todas as sociedades. O segundo é o ser moral independente, autônomo, não-social, que representa a ideologia moderna do homem e da sociedade.

No Orkut, tal como Dumont (1985) propõe, o homem busca a personalidade autossuficiente, mas também se concentra na diferenciação e na desigualdade, pois almeja o crescimento mútuo entre os seus pares que advém por meio da troca. A igualdade, então, é substituída pela desigualdade.

Algo também muito útil nesse ambiente virtual é a indicação com nome, foto e data dos aniversariantes do mês. Isso faz com que o usuário não esqueça a data de aniversário de um "amigo". Além disso, no Orkut o usuário pode compartilhar com seus "amigos" e interessados em fazerem parte de seu grupo de relacionamentos seus gostos, preferências, fotos, vídeos. Ao mesmo tempo em que ele pode também desfrutar ou "bisbilhotar" das experiências, gostos e preferências de outros usuários.

O Orkut aparece neste contexto como um espaço no qual se dá o jogo de papéis sociais em que as pessoas/usuários agem em relação às coisas e às situações baseandose unicamente no significado que estas tenham para elas. Vale ressaltar, entretanto, que estes significados são resultantes da sua interação social e modificados por sua interpretação.

Tratar o Orkut como um espaço no qual se dá o jogo de papéis sociais, remete à ideia de teatralização trabalhada por Goffman (1975), na qual um ator atua em uma posição onde há o palco e os bastidores; há relação entre a peça e a sua atuação; ele está sendo visto por um público, mas, ao mesmo tempo, ele é o público da peça encenada pelos espectadores. Neste contexto, assim como o usuário escolhe a comunidade que deseja se filiar e como se apresentar diante dos membros desta comunidade, $\mathrm{o}$ ator social tem a habilidade de escolher o seu palco e a sua peça assim como o figurino que ele usará para cada público. O objetivo principal do ator é manter sua coerência e se ajustar de acordo com a situação. Isso é feito, principalmente, através da interação com os outros atores.

De acordo com Goffman (1975), desempenhamos todos os papéis diferentes em diferentes situações sociais, e, nesse sentido, a relação com o outro é sempre complexa e problemática seja na rede ou fora dela.

Goffman (1988), orientado para as relações face a face, discute as expectativas em relação ao comportamento do outro que existem nestas relações.

Numa situação em que um indivíduo é apresentado ao outro, este prevê uma série de atributos daquele de acordo com os primeiros aspectos que aquele apresenta. $O$ conjunto de tais atributos é denominado identidade social. (GOFFMAN, 1988). 
O mesmo autor afirma ainda que em situações como esta (contato inicial com outrem), em geral, transformamos as pré-concepções em expectativas normativas, mantendo exigências rigorosas sobre as condutas do outro. Tais expectativas e exigências configuram o que ele denomina de identidade social virtual. O indivíduo em interação poderá comprovar ou desmentir as expectativas, apresentando sua identidade social real e nos casos em que o indivíduo apresenta determinado atributo indesejável, que o descredencia para a relação, apresenta um estigma ${ }^{12}$ (GOFFMAN, 1988).

Transladando esta realidade ao ambiente da comunidade virtual, podemos observar que o usuário, como um ator, pode ser quem ele quiser e pode se manifestar de maneira que ele não necessariamente corresponda ao seu padrão costumeiro de comportamento. Dessa forma, a comunidade pode se tornar o palco do usuário que representa papéis que podem ser condenados no espaço da casa e no espaço da rua.

A leitura proposta neste artigo vai ao encontro do que DaMatta (1997) defende ao propor que o Brasil constitui uma sociedade com um sistema dotado de múltiplas esferas de ação e significação social, na qual a "pedra de toque" é a capacidade de relacionar e de criar uma posição intermediária, na qual se traduz em uma linguagem de conciliação, negociação e gradação, entre os espaços.

\section{CONSIDERAÇÕES FINAIS}

Como proposto na argumentação teórica e no exemplo do Orkut citado, podemos perceber que a sociedade atual encontra-se estruturalmente marcada pelas mudanças advindas das Novas Tecnologias de Informação e Comunicação. E, no caso particular da sociedade brasileira, observamos ainda que pode haver uma afinidade entre a forte presença das relações nesta sociedade e o consumo de comunidades virtuais que possui como objetivo primário fortalecer relações sociais.

Dessa forma, acreditamos, com base nas proposições de DaMatta $(1986,1997)$, que a intensa presença dos brasileiros nas redes sociais pode ser fortemente influenciada pelo fato de o Brasil ser fundamentado em uma sociedade relacional.

As comunidades virtuais mostram-se como os espaços ideais para o fortalecimento do sentimento de religação e para suprir a falta dos "terceiros lugares" - responsáveis pela intensificação das relações sociais.

Podemos somar a isso o fato de que, nesse ambiente, encontramos de forma clara a conexão entre os espaços de significação da casa e da rua, fortalecendo a tese de DaMatta (1997), que argumenta que para o entendimento de uma sociedade é necessário estudar o que está entre os elementos, e não somente as partes que o compõem.

Nesse sentido, devemos compreender o fenômeno das comunidades virtuais para além do problema do excesso ou para além do mero narcisismo. Trata-se de uma nova forma de sociabilidade trazida à tona pelas tecnologias digitais. Assim, ver o outro e ser visto, trocar mensagens e entrar em fóruns de discussão é, de alguma forma, buscar o sentimento de religação. As comunidades virtuais instauram novas formas de exercício da sociabilidade e as práticas comunicacionais atuais da cibercultura mostram a pregnância social para além da assepsia ou simples robotização. 
Os aspectos levantados neste artigo permitem uma reflexão inicial sobre um dos possíveis motivos que podem explicar a rápida adesão dos brasileiros às comunidades virtuais. Além de apresentar algumas características predominantes da sociedade brasileira e sua influência na emergência e fortalecimento das comunidades virtuais no Brasil, o que favorece o vislumbre futuro de uma discussão mais profunda sobre o tema.

\section{REFERÊNCIAS BIBLIOGRÁFICAS}

BAUMAN, Zygmunt. Comunidade: a busca por segurança no mundo atual. Rio de Janeiro: Jorge Zahar, 2003.

CASTELLS, Manuel. A sociedade em rede: a era da informação - economia, sociedade e cultura. 3. ed. São Paulo: Paz e Terra, 1999. v. 1.

DAMATTA. Roberto. O que faz o Brasil, Brasil. Rio de Janeiro: Rocco, 1986.

A casa \& a rua: espaço, cidadania, mulher e morte no Brasil. 5. ed. Rio de Janeiro: Rocco, 1997.

DUMONT, Louis. O individualismo: uma perspectiva antropológica da sociedade moderna. Tradução de Álvaro Cabral. Rio de Janeiro, Rocco, 1985.

GOFFMAN, Erving. A Representação do eu na vida cotidiana. Petrópolis: Vozes, 1975.

Estigma: notas sobre a manipulação da identidade deteriorada. 4. ed. Rio de Janeiro: LTC, 1988.

IBOPE/NetRatings. Redes Sociais. São Paulo, 2008.

LEMOS, André L. M. As estruturas antropológicas do cyberespaço. In: Textos de Cultura e Comunicação, n. 35. Bahia: Facom/Ufba, 1996. Disponível em: <http://www.facom.ufba.br/ciberpesquisa/lemda os/ artigos.html >. Acesso em: 16 jan. 2009.

LÈVY, Pierre. Cibercultura. São Paulo: Editora 34, 1999.

RECUERO, Raquel. Comunidades virtuais: uma abordagem teórica. In: SEMINÁRIO INTERNACIONAL DE COMUNICAÇÃO, 2001, Porto Alegre. Anais eletrônicos. Porto Alegre: PUCRS, 2001.

RECUERO, Raquel. Redes sociais na internet. Porto Alegre: Sulina, 2009. 191p.

RHEINGOLD, Howard. A comunidade virtual. Lisboa: Gradiva, 1996.

RIBAS, Claudia S. C.; ZIVIANI, Paula. Redes de informação: novas relações sociais. Revista de Economía Política de las Tecnologías de la Información y Comunicación, v. X, n. 1, enero/abr. 2008. Disponível em: http/ /: www.eptic.com.br>. Acesso em: 16 jan. 2009.

SCARABOTO, Daiane. Comunidades virtuais com grupos de referência nos processos decisórios do consumidor. 2006. 155f. Dissertação (Mestrado em Administração)-Escola de Administração da Universidade Federal do Rio Grande do Sul, Porto Alegre, 2006.

OLDENBURG, Ray. The great good place: cafés, coffe shops, community centers, beauty parlors, general stores, bars, hangouts and how they get you through the day. Nova lorque: Paragon House, 1991.

ORKUT. Disponível em: <http://www.orkut.com.br >. Acesso em: 16 jan. 2009.

WEBER, Max. Conceitos básicos de Sociologia. São Paulo: Moraes, 1987. 